Session 3555

\title{
Teaching an Engineering Class for the First Time
}

\author{
Kawintorn Pothanun and William R. Peterson \\ Department of Engineering Management and Systems Engineering \\ Old Dominion University
}

\begin{abstract}
There are many graduate students in engineering departments who are assigned to teach a course at the undergraduate level as their first college teaching assignment. Many graduate teaching assistants will have a difficult time in preparing for the course (i.e., deciding what the structure of the course and examinations should be, what grading policy should be used, what presentation tools and techniques should be used, and many other issues). I have found limited publications based on direct experiences in teaching an engineering course for the first time.
\end{abstract}

This paper describes a first teaching experience from (including the structure of teaching materials, the structure of exams, the benefits of short quizzes, developing a grading policy, and experimenting with presentation tools and techniques) the point of view of a graduate student. This paper describes why teaching a course during their graduate studies is important for graduate students who want to pursuit a career in academia. Recommendations are made for including the teaching of a basic level undergraduate engineering course as a component of preparation for the professorate. The paper concludes with comments from the student's faculty advisor.

Introduction

It is not uncommon for graduate students in engineering to be assigned to teach a course at the undergraduate level during their student years. For many this is their first teaching assignment. I was one of these graduate students. I was assigned to teach an engineering economics course at the undergraduate level in the Fall 2003 semester at Old Dominion University (ODU). There were 36 students in my class. All of them had either junior or senior standing in their departments. They were from various departments, i.e., Civil Engineering, Electrical/Computer Engineering, Engineering Technology, Mechanical Engineering, and Computer Science.

New educators, especially graduate students, in the field of engineering are often unfamiliar with the specific engineering body of knowledge in an assigned course, as 
they may not have any direct experience or they may have been exposed to the field in a different environment ${ }^{1}$. While it is uncommon for graduate assistants not to have taken the course that they teach, this unfamiliarity may be more prevalent in some engineering areas such as engineering economics due to the variety of subject matter taught. Most graduate students may not have taken a class which emphasizes how to teach an engineering class. I leaned how to teach an engineering class by observation in the many engineering classes I took at the undergraduate and graduate levels. At Old Dominion University, I attended the Graduate Teaching Assistant Institute prior teaching my first engineering class. I found this one-day seminar very helpful in preparation.

Fortunately, the engineering department typically selects the course textbook for the assigned graduate teaching assistant. As a new educator, I received a syllabus from the professor who often teaches this course. I found it was very useful in designing my own syllabus.

\section{Know Your Students}

I found it was very important to know my students. A useful technique that will assist in learning the students' names and more about them is to collect some basic information. In the very first class, I asked my students to send me an email containing basic information about them. It may include (1) name, (2) preferred name, (3) student ID, (4) hometown and state, (5) local phone, (6) local address, (7) major, (8) advisor, (9) class (Fr., So., Jr., Sr.), (10) organizations, (11) occupation goals, (12) experience related to engineering economics, (13) current position if employed, (14) expected grade, and (15) class expectations. This information helped me knew my students and their expectations. Therefore I could design, adapt, or adjust context of the class to suit my students' needs.

\section{Grading Policy}

I found it was very critical to clarify your grading policy with your students from the beginning of the class. Table 1 and Table 2 were my grading policy and show the distribution of different graded elements to the total grade. Instead of having one or two midterm exams, I gave five during semester exams. In this way, each exam covered a small amo unt of new material. End of chapter quizzes comprised 10 percent of the total grade. The main purpose of end of chapter quizzes was to re-capture the main concept of each chapter. There were two case studies in my class. Each of them comprised 10 percent of the total.

\begin{tabular}{|l|r|}
\hline During semester exams (5 exams) & $45 \%$ \\
\hline Final exam & $25 \%$ \\
\hline End of chapter quizzes & $10 \%$ \\
\hline Two case studies & $20 \%$ \\
\hline Total & $100 \%$ \\
\hline
\end{tabular}

Table 1. Percent distribution of the total grade 


\begin{tabular}{|l|l|l|l|}
\hline Letter Grade & Points & Letter Grade & Points \\
\hline A & $100-94$ & C & $76-72$ \\
\hline A- & $93-90$ & C- & $71-70$ \\
\hline B+ & $89-87$ & D+ & $69-67$ \\
\hline B & $86-82$ & D & $66-62$ \\
\hline B- & $81-80$ & D- & $61-60$ \\
\hline C + & $79-77$ & F & $<60$ \\
\hline
\end{tabular}

Table 2. Grading Policy

The Structure of the Class

I found it was very useful to divide the topical outline into three to five major sections. I also created a diagram similar to Figure 1 to show the relationships between topical outline, exams and cumulative percentage of material in the course. Students found this diagram help them understand the overall picture of the course. For example, my engineering economics course was divided into four major sections. The first two sections covered about $70 \%$ of the overall class. The third section covered about $20 \%$ and the last section covered only $10 \%$. I found this was a good approach.

\section{Topical Outline}

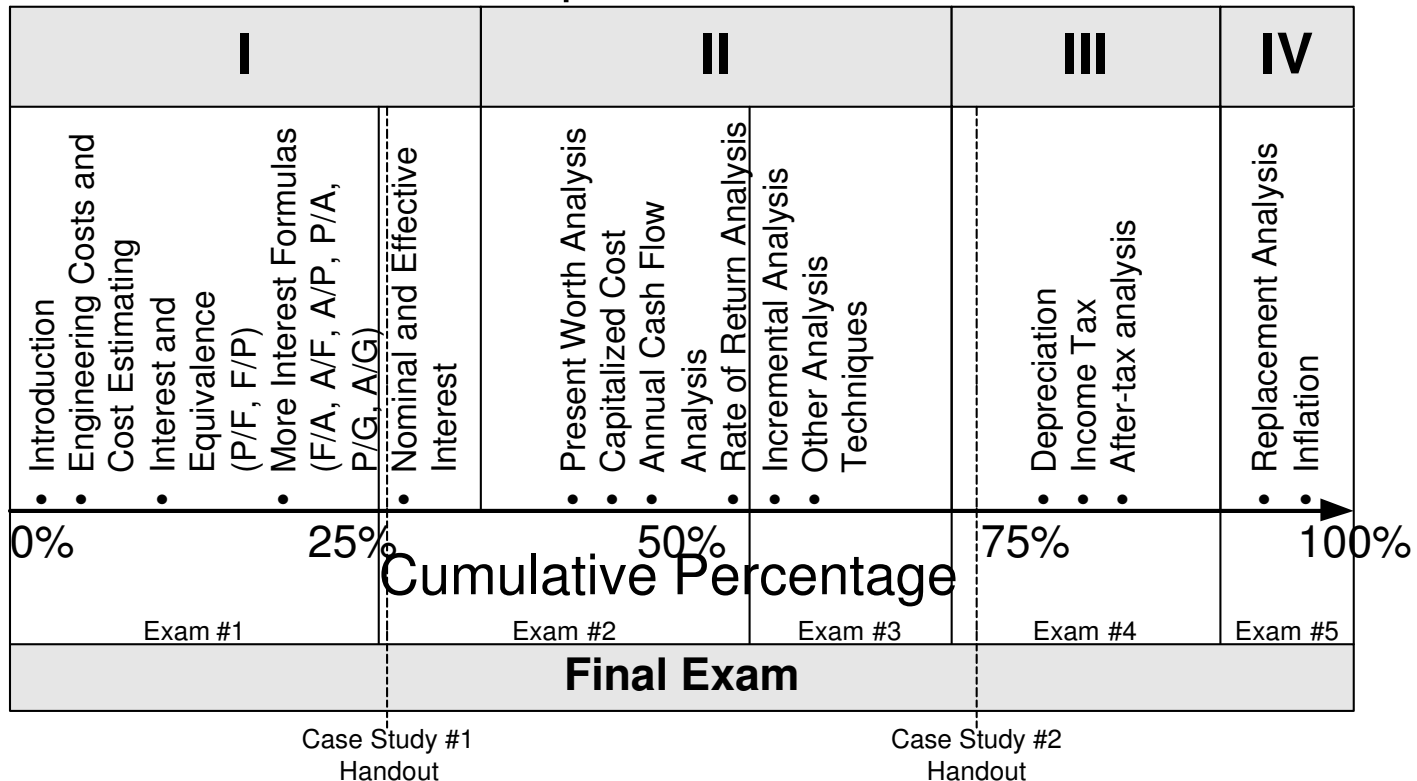

Figure 1. An example of relationship of during semester exams and topical outline

Class Preparation

It took me about 4 hours for preparation for each 75 minute lecture. I normally e-mailed the class my slides 24 hours prior to the class. In this way, students had time to review materials before coming to the class. At Old Dominion University graduate assistants should have at least 4 hours of office hours weekly. I set my office hours as the two hours prior to the class. I found that quick response to e-mail was highly recommended. I found 
that it was another way to show you paid close attention to your students. I usually responded to e-mail within 24 hours.

The Structure of Exams

The during-semester exams and the final exam consisted of short answer questions, basic or easy questions, moderate questions, and difficult questions. Short answer questions were used to demonstrate how well specific engineering concepts and terms were understood and could be articulated by the students ${ }^{2}$.

\begin{tabular}{|l|c|}
\hline \multicolumn{1}{|c|}{ Type of Question } & Percentage \\
\hline Short answer (writing) & $20 \%$ \\
\hline Basic/Easy level (calculation) & $20 \%$ \\
\hline Moderate level (calculation) & $40 \%$ \\
\hline Difficult (calculation) & $20 \%$ \\
\hline
\end{tabular}

Table 3. Structure of each exam

The structure of the exams is shown in Table 3. The first during semester exam covered about $25 \%$ of the course material. After the first exam, the first case study was handed out. The second exam covered another $30 \%$ of the course material. The third exam covered about $15 \%$ more material. The second case study was handed out when I reached the $70 \%$ cumulative mark of the course material. The fourth exam covered an additional $20 \%$. The last during semester exam covered the remaining $10 \%$.

Presentation Tools and Techniques

I mainly used the chalkboard and an overhead projector. The chalkboard is very good for demonstrating basic calculations such as homework, quiz, and exam solutions. I found that the students would write when I wrote on the chalkboard. It is also a good tool for presenting an overall picture or main concept of each topic. When using the chalkboard, I always printed letters large and neatly. I found that students had no problems reading my handwriting. I used the overhead projector at the beginning of each lecture to present outline, graphics, definitions, examples, or tables related to that class.

International Graduate Assistants

As an international engineering graduate assistant, I had a problem teaching in the English language. I overcame this problem by speaking slowly and clearly as much as I could. I also used a lot of graphics in class. My students found these techniques were very helpful.

Benefits

I gained a lot of teaching experience through my work on the engineering economics course. I was exposed to the real environment of teaching. Moreover, I gained a better 
understanding of the engineering topics that I taught. In summary, this experience helped me and will help other graduate students prepare for the professorate.

\section{Recommendations}

Teaching a course is important for graduate assistants who want to pursue a career in academia. I found a limited availability of seminars or classes for preparing engineering graduate students for teaching an engineering course for the first time. Engineering departments should provide more information and assistance to their graduate assistants on how to teach an engineering class.

Concluding Comments by the Faculty Advisor

While increasingly in recent years the emphasis for faculty seems to less on teaching and more on research, the basic premise continues that a faculty member is a teacher. To this end it seems that an integral component of doctoral education would be a teaching component.

As the faculty advisor for this graduate student, I felt it was important that he have the opportunity to be in front of a class for an entire course and to learn this element of his future "trade" while still a student. This serves many purposes. The dissertation prepares the student to do research. A teaching assignment allows the student to better understand the other major element of the professorate workload. It allows the department to graduate a "work ready" product. It allows the student to have a one course repertoire to build on and to better understand how the student's are reacting to their teaching style. It allows the student an opportunity to better evaluate academia as a future career.

In securing a teaching assignment for a graduate student, I always try to have them teach a course I normally teach - thus I am in the position to mentor the student. I am also in the position of being able to identify problems before they occur. This also allows me to share a current syllabus, be able to insure that the book is a "good" one, and otherwise serve as a resource for the graduate student (like sharing my case studies). It is also important that I serve as both a mentor and a supervisor - I must insure that the students in the course get the instruction that they deserve and at the same time insure that it is a valid learning experience for the graduate teaching assistant - not presenting my notes for me.

While making the assignment, I made sure the graduate teaching assistant knew it was his course to teach. I passed along my teaching philosophy but made sure he understood what worked for me might not work for him and he would need to structure things to suit his style.

During the experience reported above, I talked to the graduate student often but I did not visit the classroom. I asked about the course but did ask to see grades, exams, or teaching materials. While I did not seek out students in the class, students in the class commented to me on how the course was going. 
In discussing the experience, we concluded that our experiences - his recent one and mine many (many) years ago - were similar. Teaching the first course as a graduate student was demanding but the benefits are substantial - an far less threatening than as a newly hired faculty member with fewer support mechanisms in place.

Bibliography

1. Hartman, J. C., J. Lavelle, R. Martinazzi, H. Nachtmann, K. Needy and P. Shull, "A Decision Tool for Developing a Course in Engineering Economy," American Society for Engineering Education Conference, Albuquerque, NM, June, 2001.

2. Instructional Resource Booklet for Graduate Teaching Assistants Academic Year 2003-2004, Old Dominion University, Norfolk, Virginia, 2003.

\section{KAWINTORN POTHANUN}

Kawintorn Pothanun is a Ph.D. candidate in the Department of Engineering Management and Systems Engineering at Old Dominion University. He received his M.S. (2000) in Engineering Management from Old Dominion University and B.S. in Industrial Engineering from Chulalongkorn University (Thailand) in 1996. His interests include engineering economic, supply chain management, decision analysis, and information visualization.

\section{WILLIAM PETERSON}

William R. Peterson is an Assistant Professor in the Department of Engineering Management at the Old Dominion University. Dr. Peterson received a BIE from Auburn University, a MBA from Kearney State College, and a Ph.D. in Industrial and Systems Engineering from The Ohio State University. His industrial experience spans 20 years and includes positions as a plant manager and as a manufacturing services manager. He is currently president of the American Society for Engineering Management. 